\title{
Comparison of the octadentate bifunctional chelator DFO*-pPhe-NCS and the clinically used hexadentate bifunctional chelator DFO-pPhe-NCS for ${ }^{89} \mathrm{Zr}$-immuno-PET
}

\author{
Danielle J. Vugts ${ }^{1}$ - Chris Klaver ${ }^{1}$ - Claudia Sewing ${ }^{1}$ - Alex J. Poot ${ }^{1} \cdot$ Kevin Adamzek $^{1}$. \\ Seraina Huegli ${ }^{2}$ - Cristina Mari $^{2}$ - Gerard W. M. Visser ${ }^{1}$ Ibai E. Valverde ${ }^{3}$. \\ Gilles Gasser $^{2}$ - Thomas L. Mindt ${ }^{4,5}$ • Guus A. M. S. van Dongen ${ }^{1}$
}

Received: 15 July 2016 / Accepted: 16 August 2016/Published online: 30 August 2016

(C) The Author(s) 2016. This article is published with open access at Springerlink.com

\begin{abstract}
Purpose All clinical ${ }^{89} \mathrm{Zr}$-immuno-PET studies are currently performed with the chelator desferrioxamine (DFO). This chelator provides hexadentate coordination to zirconium, leaving two coordination sites available for coordination with, e.g., water molecules, which are relatively labile ligands. The unsaturated coordination of DFO to zirconium has been suggested to result in impaired stability of the complex in vivo and consequently in unwanted bone uptake of ${ }^{89} \mathrm{Zr}$. Aiming at clinical improvements, we report here on a bifunctional isothiocyanate variant of the octadentate chelator $\mathrm{DFO}^{*}$ and the
\end{abstract}

Electronic supplementary material The online version of this article (doi:10.1007/s00259-016-3499-x) contains supplementary material, which is available to authorised users.

Danielle J. Vugts

d.vugts@vumc.n

Gilles Gasser

gilles.gasser@chem.uzh.ch

$\triangle$ Thomas L. Mindt

t.mindt@gmx.ch

1 Department of Radiology \& Nuclear Medicine, VU University Medical Center, De Boelelaan 1085, loc. Radionuclide Center, 1081HV Amsterdam, The Netherlands

2 Department of Chemistry, University of Zurich, Zurich, Switzerland

3 Division of Radiopharmaceutical Chemistry, University of Basel Hospital, Basel, Switzerland

4 ETH Zurich, Institute of Pharmaceutical Sciences, Vladimir-Prelog Weg 4, CH-8093 Zurich, Switzerland

5 Ludwig Boltzmann Institute for Applied Diagnostics, General Hospital of Vienna, Vienna, Austria in vitro and in vivo comparison of its ${ }^{89} \mathrm{Zr}-\mathrm{DFO} *-\mathrm{mAb}$ complex with ${ }^{89} \mathrm{Zr}$-DFO-mAb.

Methods The bifunctional chelator DFO*- $p$ Phe-NCS was prepared from previously reported $\mathrm{DFO}^{*}$ and $p$ phenylenediisothiocyanate. Subsequently, trastuzumab was conjugated with either DFO*-p Phe-NCS or commercial DFO- $p$ Phe-NCS and radiolabeled with $\mathrm{Zr}-89$ according to published procedures. In vitro stability experiments were carried out in saline, a histidine/sucrose buffer, and blood serum. The in vivo performance of the chelators was compared in N87 tumor-bearing mice by biodistribution studies and PET imaging.

Results In $0.9 \% \mathrm{NaCl}^{89} \mathrm{Zr}$-DFO*-trastuzumab was more stable than ${ }^{89} \mathrm{Zr}$-DFO-trastuzumab; after $72 \mathrm{~h}$ incubation at $2-8{ }^{\circ} \mathrm{C} 95 \%$ and $58 \%$ intact tracer were left, respectively, while in a histidine-sucrose buffer no difference was observed, both products were $\geq 92 \%$ intact. In vivo uptake at $144 \mathrm{~h}$ post injection (p.i.) in tumors, blood, and most normal organs was similar for both conjugates, except for skin, liver, spleen, ileum, and bone. Tumor uptake was $32.59 \pm 11.95$ and $29.06 \pm 8.66 \% \mathrm{ID} / \mathrm{g}$ for ${ }^{89} \mathrm{Zr}$-DFO*trastuzumab and ${ }^{89} \mathrm{Zr}$-DFO-trastuzumab, respectively. The bone uptake was significantly lower for ${ }^{89} \mathrm{Zr}-\mathrm{DFO} *$ trastuzumab compared to ${ }^{89} \mathrm{Zr}$-DFO-trastuzumab. At $144 \mathrm{~h}$ p.i. for ${ }^{89} \mathrm{Zr}-\mathrm{DFO} *$-trastuzumab and ${ }^{89} \mathrm{Zr}$-DFOtrastuzumab, the uptake in sternum was $0.92 \pm 0.16$ and $3.33 \pm 0.32 \% \mathrm{ID} / \mathrm{g}$, in femur $0.78 \pm 0.11$ and $3.85, \pm 0.80$ and in knee $1.38 \pm 0.23$ and $8.20 \pm 2.94 \% \mathrm{ID} / \mathrm{g}$, respectively. The uptake in bone decreased from $24 \mathrm{~h}$ to $144 \mathrm{~h}$ p.i. about two fold for the DFO* conjugate, while it increased about two fold for the DFO conjugate.

Conclusions Zr-DFO*-trastuzumab showed superior in vitro stability and in vivo performance when compared to ${ }^{89} \mathrm{Zr}$-DFO-trastuzumab. This makes the new octadentate 
$\mathrm{DFO}^{*}$ chelator a candidate successor of DFO for future clinical ${ }^{89} \mathrm{Zr}$-immuno-PET.

Keywords Immuno-PET $\cdot{ }^{89} \mathrm{Zr} \cdot \mathrm{DFO} *$. DFO $\cdot$ Monoclonal antibodies

\section{Introduction}

PET imaging with ${ }^{89} \mathrm{Zr}$-labeled monoclonal antibodies (mAbs) or other targeted vehicles (e.g., peptides, nanoparticles, and cells), collectively called ${ }^{89} \mathrm{Zr}$-immuno-PET, can be used for better understanding of disease targets and the in vivo behavior of targeted drugs [1]. ${ }^{89} \mathrm{Zr}$ is ideally suited for this purpose because its physical half-life of $78.4 \mathrm{~h}$ matches the residence time of intact $\mathrm{mAbs}$ in the body (typically several days). Moreover, ${ }^{89} \mathrm{Zr}$ is a residualising radionuclide; when a $\mathrm{mAb}$ internalises, ${ }^{89} \mathrm{Zr}$-mAbs give higher tumor-to-normal tissue ratios than, e.g., the corresponding ${ }^{124}$ I-labeled mAbs [2] resulting in better contrast on PET images.

The field of ${ }^{89} \mathrm{Zr}$-immuno-PET is expanding very rapidly as exemplified by the increasing number of publications in recent years, the types of applications, and the number of clinical trials $[1,3]$. Several factors are contributing to this rapid expansion. First, mAbs are entering the mainstream of targeted drug development and therapy [4]. The recent introduction of the next generation of mAbs, characterised by increased potency (e.g., antibody-drug conjugates and immune checkpoint inhibiting mAbs), multiple binding domains, and/ or high costs, makes finding answers about their in vivo behavior in individual subjects even more urgent [5]. Second, ${ }^{89} \mathrm{Zr}$-immuno-PET appears to be ideally suited for quantitative imaging of mAbs, and became technically matured by the commercial supply of ${ }^{89} \mathrm{Zr}$ and chelators, standard protocols for ${ }^{89} \mathrm{Zr}$ coupling to $\mathrm{mAbs}$, and standardisation and harmonisation of ${ }^{89} \mathrm{Zr}$-quantification by PET imaging [6-8].

The only chelator used thus far in the clinic for the complexation of ${ }^{89} \mathrm{Zr}$ is desferrioxamine (DFO). The fact that DFO was clinically used for many years to counteract iron and aluminum overload, has clearly facilitated the introduction of DFO in clinical ${ }^{89} \mathrm{Zr}$-immuno-PET. Moreover, the first clinical ${ }^{89} \mathrm{Zr}$-immuno-PET trial indicated that the chelator is not immunogenic [9], and can, therefore, be used repeatedly. The most often used conjugation procedures employ a 2,3,5,6tetrafluorophenol (TFP) activated ester of $N$-succinyl-DFOFe (TFP- $N$-suc-DFO-Fe, in which DFO is protected by $\mathrm{Fe}^{3+}$ ) or $p$-isothiocyanatobenzyl-DFO ( $p$-SCN-Bn-DFO = DFO$p$ Phe-NCS, Macrocyclics), forming stable amide or thiourea bonds, respectively, with lysine residues of the proteins [6, 10-12]. Both bifunctional chelating agents are commercially available and have been applied in clinical trials.

From an inorganic chemistry perspective, however, DFO is not the optimal chelator for stable complexation of zirconium, because DFO consists of three hydroxamate moieties and is a hexadentate chelator, while ${ }^{89} \mathrm{Zr}^{4+}$ prefers the formation of octadentate complexes [13]. Although the resulting slightly impaired stability of ${ }^{89} \mathrm{Zr}$-DFO-mAb does not really hamper image quality, it is clear from preclinical studies that in time, some ${ }^{89} \mathrm{Zr}^{4+}$ becomes released from the conjugate and accumulates in the bones [13-16]. For example, Perk et al. compared the biodistribution of the conjugates ${ }^{89} \mathrm{Zr}-\mathrm{DFO}$ cetuximab, ${ }^{88}$ Y-DOTA-cetuximab and ${ }^{177}$ Lu-DOTAcetuximab in tumor-bearing nude mice [14]. While the overall biodistribution of these conjugates was very similar, a significant higher uptake for ${ }^{89} \mathrm{Zr}$ compared to ${ }^{88} \mathrm{Y}$ and ${ }^{177} \mathrm{Lu}$ was observed in femur and sternum at 48-144 h p.i. Over time, femur levels increased from about $2 \% \mathrm{ID} / \mathrm{g}$ at $24 \mathrm{~h}$ p.i. to 6.9 $\%$ ID/g at $144 \mathrm{~h}$ p.i., indicating partial instability of the ${ }^{89} \mathrm{Zr}$ DFO complex. Bone uptake of released ${ }^{89} \mathrm{Zr}$ is unwanted, since it will increase the radiation dose to the bone marrow, impair detection of bone metastases, and disturb ${ }^{89} \mathrm{Zr}-\mathrm{mAb}$ quantification in bone, bone marrow, and bone metastases.

An optimal chelating agent should be safe for clinical use, efficiently conjugated to, e.g., mAbs and labeled with ${ }^{89} \mathrm{Zr}$, not alter the biodistribution of the mAb, and, most importantly, be more stable in vitro and in vivo than DFO to prevent gradual accumulation of ${ }^{89} \mathrm{Zr}$ in the bones. In the past years, several new chelators have been reported aiming at increased ${ }^{89} \mathrm{Zr}$-complex stability in vivo. Some chelators contain hydroxamate moieties, like the linear and macrocyclic tetrahydroxamate chelators reported by Guerard et al., and the trihydroxamate chelators reported by Boros et al. and Zhai et al. [17-20]. Other examples do not contain hydroxamate moieties like $p$-SCN-Bn-H6phospha, 3,4,3-(LI1,2-HOPO), and 3-hydroxypyridin-2-one (2,3-HOPO) [16, 21-23]. However, none of these developments have led to a bifunctional chelator that outperforms ${ }^{89} \mathrm{Zr}$-DFO-mAb complexes on all abovementioned aspects of an optimal chelating agent.

Recently, we reported the synthesis of a tetrahydroxamate chelator called DFO* (DFO-star), and the high stability of its ${ }^{89} \mathrm{Zr}$-DFO*-complex as shown in challenging experiments with DFO [24]. In the current paper, we describe the synthesis of the bifunctional DFO*-pPhe-NCS, its coupling to mAbs, and the subsequent labeling with ${ }^{89} \mathrm{Zr}$. Finally, ${ }^{89} \mathrm{Zr}-\mathrm{DFO} *_{-}$ mAb conjugates are compared with ${ }^{89} \mathrm{Zr}$-DFO-mAb conjugates for stability in vitro, and for biodistribution and PET imaging in vivo in tumor-bearing mice with emphasis on ${ }^{89} \mathrm{Zr}$ bone uptake.

\section{Materials and methods}

Details regarding the synthesis and analysis of DFO*-pPheNCS, radiolabeling results of cetuximab and rituximab, and examples of SEC-HPLC diagrams of ${ }^{89} \mathrm{Zr}-\mathrm{DFO}{ }^{*}$ 
trastuzumab, ${ }^{89} \mathrm{Zr}-\mathrm{DFO}{ }^{*}$-rituximab, and ${ }^{89} \mathrm{Zr}-\mathrm{DFO}{ }^{*}$ cetuximab can be found in the supplemental data.

\section{Materials, monoclonal antibodies, cell lines, radioactivity, and nomenclature}

All reagents and solvents were purchased from Sigma Aldrich. Trastuzumab $(21 \mathrm{mg} / \mathrm{mL})$ directed against human epidermal growth factor receptor 2 (HER2), cetuximab $(5 \mathrm{mg} / \mathrm{mL})$ directed against the epidermal growth factor receptor (EGFR), and rituximab $(10 \mathrm{mg} / \mathrm{mL})$ directed against CD20, were obtained from the VU University Medical Center pharmacy. In the present study, DFO*-pPhe-NCS is compared with DFO- $p$ Phe-NCS, which is commercially available from Macrocyclics under the name $p$-SCN-Bn-deferoxamine. Both compounds have the same $p$ isothiocyanatophenylurea linker attached to DFO or DFO*, respectively, and will be designated ${ }^{89} \mathrm{Zr}-\mathrm{DFO}\left({ }^{*}\right)-\mathrm{mAb}$ throughout the manuscript. The human gastric cancer cell line NCI-N87 was obtained from ATCC (United Kingdom) after cytogenetic testing and used within 6 months after resuscitation of the frozen cell line. The immunoreactivity was determined using SKOV-3 (HER2), A431 (EGFR), or SU-DHL-4 (CD20) cells essentially as described by Lindmo et al. [25]. ${ }^{89} \mathrm{Zr}(\geq 0.15 \mathrm{GBq} / \mathrm{nmol}$ in $1 \mathrm{~mol} / \mathrm{L}$ oxalic acid) was obtained from Perkin Elmer, Boston, USA.

\section{General analyses and procedures}

Cetuximab $(5 \mathrm{mg} / \mathrm{mL})$ was rebuffered to $0.9 \% \mathrm{NaCl}$ with the aid of size exclusion chromatography using PD10 columns (GE Healthcare Life Sciences) and re-concentrated to 5 or $5.77 \mathrm{mg} / \mathrm{mL}$ by a spin filter (Microcon-10 centrifugal filter, Merck Millipore). Trastuzumab $(21 \mathrm{mg} / \mathrm{mL})$ and rituximab $(10 \mathrm{mg} / \mathrm{mL})$ were used as such and diluted to 5 or $5.77 \mathrm{mg} /$ $\mathrm{mL}$ with $0.9 \% \mathrm{NaCl}$.

Nanodrop analyses were performed on a NanoVue Plus (GE Healthcare Life Sciences). Spin filter separation was performed to determine the radiochemical purity. To this end $4 \mu \mathrm{L}$ of sample was diluted with $96 \mu \mathrm{L}$ eluent (5\% DMSO and $95 \% 20 \mathrm{mM}$ histidine $/ 240 \mathrm{mM}$ sucrose buffer $\mathrm{pH} 5.5-$ 5.8) and applied on a microcon-30 centrifugal filter unit (Ultracel YM-30, regenerated cellulose, $30 \mathrm{kDa}$ cut-off, Merck Millipore). The solution was spun down for $7 \mathrm{~min}$ at 14,000 rpm (Eppendorf 5430). The filter was washed twice with $100 \mu \mathrm{L}$ eluent and spun down at 14,000 rpm for $7 \mathrm{~min}$ after each wash step. The filtrate contained free ${ }^{89} \mathrm{Zr} /{ }^{89} \mathrm{Zr}$ $\mathrm{DFO}(*)$, while the radiolabeled $\mathrm{mAb}$ was left on the filter. Size exclusion (SE)-HPLC was performed to determine protein integrity and radiochemical purity. SE-chromatography was performed on a Jasco HPLC system equipped with a superdex ${ }^{\mathrm{TM}} 200$ 10/30 GL size exclusion column (GE Healthcare Life Sciences) or Zenix SEC-300 (3 $\mu \mathrm{m}, 300 \AA$,
$7.8 \times 50 \mathrm{~mm}$, Sepax) column including a guard column using a mixture of $0.05 \mathrm{M}$ sodium phosphate, $0.15 \mathrm{M}$ sodium chloride ( $\mathrm{pH} 6.8$ ), and $0.01 \mathrm{M} \mathrm{NaN}_{3}$ as the eluent at a flow rate of $0.5 \mathrm{~mL} / \mathrm{min}$ or $1 \mathrm{~mL} / \mathrm{min}$, respectively. The radioactivity of the eluate was monitored using an inline $\mathrm{NaI}(\mathrm{Tl})$ radiodetector (Raytest Sockett). HPLC monitoring of the final products was performed on a Jasco HPLC system using a superdex 200 column. Serum stability samples were analysed on a Zenix SEC-300 using the same eluent as the superdex 200 column. The iTLC analysis was performed to determine the radiolabeling efficiency of DFO*- $p$ Phe-NCS and DFO$p$ Phe-NCS with ${ }^{89} \mathrm{Zr}$ using iTLC-SG (Agilent Technologies, Santa Clara, CA, USA) and $50 \mathrm{mM}$ DTPA $\mathrm{pH}=7$ as mobile phase (11.5 cm strip, 8 min run time). ${ }^{89} \mathrm{Zr}$-DFO*-p Phe-NCS had a $\mathrm{R}_{\mathrm{f}}=0-0.25,{ }^{89} \mathrm{Zr}$-DFO- $p$ Phe-NCS a $\mathrm{R}_{\mathrm{f}}=0$, and free ${ }^{89} \mathrm{Zr}$ a $\mathrm{R}_{\mathrm{f}}=1$.

\section{Preparation of ${ }^{89} \mathrm{Zr}-\mathrm{DFO} \mathrm{*}_{-}-\mathrm{mAb}$ and ${ }^{89} \mathrm{Zr-DFO-mAb}$}

The $\mathrm{pH}$ of the $\mathrm{mAb}$ solution $(5 \mathrm{mg} / \mathrm{mL})$ was adjusted to 8.9 9.1 with $0.1 \mathrm{M} \mathrm{Na}_{2} \mathrm{CO}_{3}$. This solution was added to 3 eq. of DFO*-pPhe-NCS or DFO-pPhe-NCS in DMSO (2 v/v\% compared to aqueous solution) and incubated for $30 \mathrm{~min}$ in a Thermomixer $(550 \mathrm{rpm})$ at $37{ }^{\circ} \mathrm{C}$. After $30 \mathrm{~min}$, nonconjugated hydrolysed chelator was removed by size exclusion chromatography using a PD-10 column and $0.9 \% \mathrm{NaCl}$ or $20 \mathrm{mM}$ histidine $+240 \mathrm{mM}$ sucrose $\mathrm{pH} 5.5-5.8$ as eluent (same eluent used as after radiolabeling). The concentration of the product was determined by spectrophotometry at $280 \mathrm{~nm}$ using NanoDrop or by a calibration curve on a superdex 200 column. Subsequently, DFO*-mAb or DFO-mAb was radiolabeled with ${ }^{89} \mathrm{Zr}$ at room temperature for $60 \mathrm{~min}$. Typically, for a $1 \mathrm{~mL}$ reaction the following protocol was used: to $100 \mu \mathrm{L}{ }^{89} \mathrm{Zr}(\sim 50 \mathrm{MBq})$ in $1 \mathrm{M}$ oxalic acid solution, $45 \mu \mathrm{L} 2 \mathrm{M} \mathrm{Na}_{2} \mathrm{CO}_{3}$ was added and reacted for $3 \mathrm{~min}$. Subsequently, $150 \mu \mathrm{L} 0.5$ M HEPES buffer ( $\mathrm{pH} 7.0$ ), $355 \mu \mathrm{L}(0.5 \mathrm{mg})$ DFO*-mAb, or DFO-mAb and $350 \mu \mathrm{L}$ 0.5 M HEPES ( $\mathrm{pH} 7.0$ ) were added (the second portion of HEPES may be added with the first portion, as long as the reaction is properly mixed after the addition of $\mathrm{mAb}$ ). Finally, ${ }^{89} \mathrm{Zr}$-DFO*-mAb or ${ }^{89} \mathrm{Zr}$-DFO-mAb was purified by size exclusion chromatography (PD10 column). The concentration of $\mathrm{DFO}(*)-\mathrm{mAbs}$ was determined by SE-HPLC on a Zenix SEC-300 column. For in vitro stability experiments with trastuzumab, the product was formulated to $0.2 \mathrm{mg} / \mathrm{mL}$ and $10 \mathrm{MBq} / \mathrm{mL}(50 \mathrm{MBq} / \mathrm{mg}$ ) (see in vitro stability section for buffer composition).

\section{Chelator-to-mAb ratio of ${ }^{89} \mathrm{Zr}-\mathrm{DFO}{ }^{*}-\mathrm{mAb}$ and ${ }^{89} \mathrm{Zr}-\mathrm{DFO}-\mathrm{mAb}$}

The chelator-to-mAb ratio was determined by prelabeling the chelator and the subsequent conjugation of ${ }^{89} \mathrm{Zr}$-chelator as 
well as by an isotopic dilution assay essentially as described by Meares et al. [26].

Prelabeling the bifunctional chelator: to $20 \mu \mathrm{L}{ }^{89} \mathrm{Zr}(2-$ $5 \mathrm{MBq}$ ) in $1 \mathrm{M}$ oxalic acid solution, $100 \mu \mathrm{L} 0.9 \% \mathrm{NaCl}$ and $9 \mu \mathrm{L} 2 \mathrm{M} \mathrm{Na}_{2} \mathrm{CO}_{3}$ were added and reacted for $3 \mathrm{~min}$. Subsequently, $100 \mu \mathrm{L} 0.5 \mathrm{M}$ HEPES buffer $(\mathrm{pH} 7.0)$ and $40 \mu \mathrm{L}$ DFO*/DFO- $p$ Phe-NCS $(5 \mathrm{mM})$ in DMSO were added. After $5 \mathrm{~min}$, half of the volume $(134.5 \mu \mathrm{L})$ was transferred to an Eppendorf vial, and to this solution $865.5 \mu \mathrm{L}$ trastuzumab, rituximab or cetuximab $(5.77 \mathrm{mg} / \mathrm{mL}$ ) were added (final concentration: $5 \mathrm{mg} / \mathrm{mL} \mathrm{mAb}$ ). The $\mathrm{pH}$ was set to 8.9-9.1 with $2 \mathrm{M} \mathrm{Na}_{2} \mathrm{CO}_{3}$, and the reaction incubated for $30 \mathrm{~min}$ in a Thermomixer $(550 \mathrm{rpm})$ at $37{ }^{\circ} \mathrm{C}$. Finally, ${ }^{89} \mathrm{Zr}-\mathrm{DFO}^{*}$ $\mathrm{mAb} /{ }^{89} \mathrm{Zr}$-DFO-mAb was purified by size exclusion chromatography (PD10 column) and the conjugation efficiency determined.

Isotopic dilution assay: the $\mathrm{DFO}(*)$-to-trastuzumab and $\mathrm{DFO}(*)$-to-rituximab molar ratios were determined following a general method as described by Meares et al. [26]. In short, conjugates were labelled according to the aforementioned procedure with a known excess of zirconium oxalate spiked with ${ }^{89} \mathrm{Zr}$.

\section{In vitro stability (aqueous solutions and blood serum)}

The in vitro stability was evaluated in two sets of experiments. In a first set of experiments, the products were formulated at $0.2 \mathrm{mg} / \mathrm{mL}$ and $10 \mathrm{MBq} / \mathrm{mL}(50 \mathrm{MBq} / \mathrm{mg})$ and stored at $4{ }^{\circ} \mathrm{C}$ and room temperature in two different solutions: $0.9 \% \mathrm{NaCl}$ or $20 \mathrm{mM}$ histidine $+240 \mathrm{mM}$ sucrose, $\mathrm{pH}$ 5.5-5.8. After 24 , 48,72 , and $168 \mathrm{~h}$ samples were analysed for radiochemical purity by a spin filter and immunoreactivity by a Lindmo assay. In a second set of experiments, the formulated products in $0.9 \% \mathrm{NaCl}$ was mixed with freshly prepared human blood serum at a 1:1 ratio, and $0.02 \%$ sodium azide was added. The samples were incubated at $37{ }^{\circ} \mathrm{C}$ in a $\mathrm{CO}_{2}$-enriched atmosphere $\left(5 \% \mathrm{CO}_{2}\right)$. At various time points, aliquots were taken and analysed for radiochemical purity by SE-HPLC on a Zenix SEC-300 column and for immunoreactivity by a Lindmo assay. In the case of serum, SE-HPLC was used for analysis of radiochemical purity, because spin filters gave less reproducible results.

\section{Evaluation of in vivo biodistribution}

The biodistribution of both ${ }^{89} \mathrm{Zr}$-DFO*-trastuzumab and ${ }^{89} \mathrm{Zr}$ DFO-trastuzumab was evaluated in N87 tumor bearing mice. Female mice (HSD:Athymic Nude-Foxn1nu, 21-31 g; Harlan) were 8 to 10 weeks old at the time of the experiments. All animal experiments were done according to the NIH Principles of Laboratory Animal Care and Dutch national law ("Wet op de dierproeven", Stb 1985, 336). Mice bearing N87 xenografts (two groups of $n=18$ ) were anesthetised by inhalation of $2 \%$ isoflurane and injected intravenously (i.v.) via the retroorbital plexus with either $100 \mu \mathrm{g}{ }^{89} \mathrm{Zr}$-DFOtrastuzumab or ${ }^{89} \mathrm{Zr}$-DFO*-trastuzumab (2 MBq) in $20 \mathrm{mM}$ histidine $+240 \mathrm{mM}$ sucrose, $\mathrm{pH}$ 5.5-5.8. Unlabeled trastuzumab was added to the injection mixture to bring the total $\mathrm{mAb}$ dose to $100 \mu \mathrm{g}$ per mouse. At $1,4,24,48,72$, and $144 \mathrm{~h}$ p.i., blood samples were drawn to determine the blood kinetics. At 24, 72, and 144 h p.i., six mice of each group were anesthetised, bled, killed, and dissected. After blood, tumor, and normal tissues had been weighed, the amount of radioactivity in each sample was measured in a gamma counter. Radioactivity uptake was calculated as the percentage of the injected dose per gram of tissue $(\% \mathrm{ID} / \mathrm{g})$.

\section{PET study}

PET imaging was performed on a dedicated small animal NanoPET/CT scanner (Mediso Ltd., Hungary, Szanda et al.). N87 xenograft-bearing nude mice ( $n=1$ for each conjugate) from the $144 \mathrm{~h}$ biodistribution timepoint were anesthetised by inhalation of $2 \%$ isoflurane and scanned at $72 \mathrm{~h}$ p.i. for $1 \mathrm{~h}$. A $\mathrm{CT}$ scan was acquired prior to the PET scan and used for attenuation and scatter correction purposes. Reconstruction was performed with a fully 3-dimensional (3-D) reconstruction (Tera-Tomo; Mediso Ltd.) with four iterations and six subsets, resulting in an isotropic $0.4 \mathrm{~mm}$ voxel dimension. The scanner was cross-calibrated with the dose calibrator and well counter, enabling the derivation of accurate SUV measures.

\section{Statistical analyses}

Statistical analysis was performed on pharmacokinetics, tissue uptake, and tumor-to-blood ratios between different groups of mice with the Welch's $T$-test (SPSS) for paired data. Twosided significance levels were calculated and $p<0.01$ was considered as statistically significant.

\section{Results}

DFO*- $p$ Phe-NCS was prepared from DFO* [24] in a single step by reaction with $p$-phenylenediisothiocyanate (Fig. 1). The product was purified by preparative HPLC and isolated in a satisfying chemical yield with a purity of $>95 \%$ according to HPLC at $275 \mathrm{~nm}$ and NMR (Figure S1-4). For conjugation to $\mathrm{mAbs}$, the product was dissolved in DMSO.

${ }^{89} \mathrm{Zr}$-DFO*-trastuzumab and ${ }^{89} \mathrm{Zr}$-DFO-trastuzumab were prepared similarly to postlabeling procedures described by Vosjan et al. [6]. Protein aggregation during modification was observed when using the Vosjan method, which could be minimised by adapting the reagent addition procedure. Instead of adding small portions of the chelator 

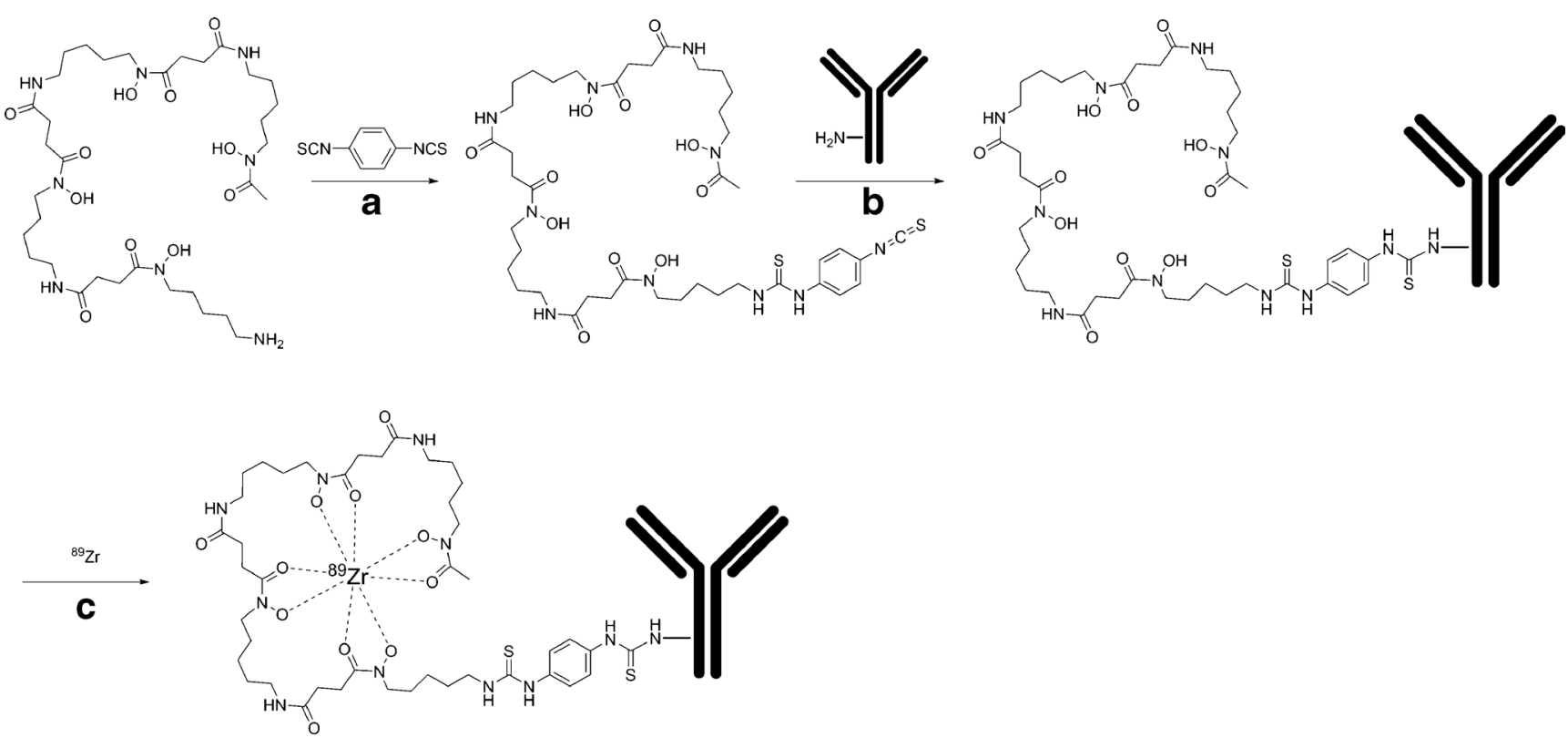

Fig. 1 Synthesis of ${ }^{89} \mathrm{Zr}$-DFO*-mAbs: a Et ${ }_{3} \mathrm{~N}, i$ PropOH/H$/ \mathrm{H}_{2} \mathrm{O} / \mathrm{CHCl}_{3}, \mathrm{RT}, 18 \mathrm{~h}$; b $30 \min 37^{\circ} \mathrm{C}$, RT; c $60 \mathrm{~min} \mathrm{RT}$

in DMSO to the mAb solution, the mAb was added at once to the chelator in DMSO. This way, the protein integrity was preserved, showing a single IgG peak at $280 \mathrm{~nm}$ at SEHPLC. All conjugates could be radiolabeled efficiently (>80\% radiolabeling yield with $0.5 \mathrm{mg} / \mathrm{mL} \mathrm{mAb}$ ) and had a radiochemical purity of $>97.5 \%$ and optimal immunoreactive fraction $(>96 \%)$. This is also true for cetuximab and rituximab, which could be radiolabeled with the same efficiency and radiochemical purity and an immunoreactive fraction $\geq 90 \%$ (see supporting information).

The DFO to mAb molar ratios as determined by the isotope dilution assay were $0.9 \pm 0.1(n=6)$ and $1.3 \pm 0.1(n=3)$ for trastuzumab and rituximab, respectively, and the $\mathrm{DFO}^{*}$ to $\mathrm{mAb}$ ratios were $0.6 \pm 0.1(n=4)$ and $0.8 \pm 0.1(n=4)$ for trastuzumab and rituximab, respectively.

Interestingly, when DFO*-pPhe-NCS and DFO-pPhe-NCS were first radiolabeled with ${ }^{89} \mathrm{Zr}$ and subsequently conjugated to the $\mathrm{mAb}$ (prelabeling approach), only for $\mathrm{DFO}^{*}$ radiolabeled $\mathrm{mAb}$ was obtained. Although DFO*-pPhe-NCS and DFO$p$ Phe-NCS did radiolabel efficiently (after $5 \mathrm{~min}$ at room temperature both compounds were $>95 \%$ radiolabeled as determined by iTLC), ${ }^{89} \mathrm{Zr}$-DFO-pPhe-NCS did not conjugate to mAbs at all. In contrast, in the case of $\mathrm{DFO}^{*}$, the applied 3:1 conjugation ratio of ${ }^{89} \mathrm{Zr}$-DFO*-p Phe-NCS to mAb resulted in $43 \pm 2,63 \pm 1$ and $43 \pm 2 \%$ radiolabeled product and, thus, a $1.3,1.9$, and 1.3 chelator-to-mAb ratio for trastuzumab $(n=4)$, rituximab $(n=2)$, and cetuximab $(n=2)$, respectively.

${ }^{89} \mathrm{Zr}$-DFO*-trastuzumab and ${ }^{89} \mathrm{Zr}$-DFO-trastuzumab obtained by standard post radiolabeling procedures were stored at $4{ }^{\circ} \mathrm{C}$ and room temperature in $0.9 \% \mathrm{NaCl}$ and $20 \mathrm{mM}$ histidine/240 mM sucrose $\mathrm{pH}$ 5.5-5.8 up to 7 days to evaluate the in vitro stability. In $0.9 \% \mathrm{NaCl}^{89} \mathrm{Zr}$-DFO*-trastuzumab outperformed ${ }^{89} \mathrm{Zr}$-DFO-trastuzumab in terms of stability (see Table 1 and Table S1); while at $4{ }^{\circ} \mathrm{C}$ only $57.6 \%$ intact ${ }^{89} \mathrm{Zr}$ DFO-trastuzumab was left after 3 days, ${ }^{89} \mathrm{Zr}-\mathrm{DFO}^{*}$ trastuzumab was still $94.5 \%$ intact after the same period of time. At room temperature, the percentage of intact tracer was $41.1 \%$ for ${ }^{89} \mathrm{Zr}$-DFO-trastuzumab and $90.7 \%$ for ${ }^{89} \mathrm{Zr}-\mathrm{DFO}{ }^{*}$ trastuzumab. In $20 \mathrm{mM}$ histidine/240 $\mathrm{mM}$ sucrose, the products exhibited no difference in stability. Both compounds were $>92 \%$ intact after 3 days of storage at $4{ }^{\circ} \mathrm{C}$ or room temperature. The immunoreactivity of the products, not corrected for free radioactivity, decreased accordingly and was following the same trend as the radiochemical purity. Also in vitro stability studies in human serum/0.9 \% NaCl (1:1) showed that ${ }^{89} \mathrm{Zr}$-DFO*-trastuzumab is more stable than ${ }^{89} \mathrm{Zr}$-DFOtrastuzumab. After $72 \mathrm{~h}$ at $37{ }^{\circ} \mathrm{C}, 97.5 \%$ and $77.7 \%$ intact tracer was left, respectively. Immunoreactivity determined by the Lindmo binding assay showed the same trend and an immunoreactive fraction of $91 \%$ and $74 \%$ was observed after $72 \mathrm{~h}$ at $37{ }^{\circ} \mathrm{C}$ for ${ }^{89} \mathrm{Zr}-\mathrm{DFO} *$-trastuzumab and ${ }^{89} \mathrm{Zr}-\mathrm{DFO}$ trastuzumab, respectively.

${ }^{89} \mathrm{Zr}$-DFO*-trastuzumab and ${ }^{89} \mathrm{Zr}$-DFO-trastuzumab were injected into N87 tumor-bearing nude mice. At 1, 4, 24, 48, 72, and $144 \mathrm{~h}$ p.i., blood samples were drawn and the $\%$ ID/g determined. At 24, 72, and $144 \mathrm{~h}$ p.i., the $\% \mathrm{ID} / \mathrm{g}$ uptake in tumor and normal tissue was determined. Blood kinetics were similar (see Fig. 2). At 144 h p.i., blood kinetics and tumor uptake were not significantly different, while bone-containing organs, skin, liver, spleen, and ileum showed a significantly lower uptake level in case of DFO* (see Fig. 3). Uptake of ${ }^{89} \mathrm{Zr}$-DFO*-trastuzumab in bone-containing organs decreased over time, while the uptake of ${ }^{89} \mathrm{Zr}$-DFO-trastuzumab increased (see Figure S5). As a result, ratios of ${ }^{89} \mathrm{Zr}$-DFO-trastuzumab 
Table 1 In vitro stability of ${ }^{89} \mathrm{Zr}$-DFO*-trastuzumab (A) and ${ }^{89} \mathrm{Zr}$-DFO-trastuzumab (B) at $4{ }^{\circ} \mathrm{C}$ in $20 \mathrm{mM}$ histidine $+240 \mathrm{mM} \mathrm{sucrose}$ or $0.9 \% \mathrm{NaCl}$ or at $37^{\circ} \mathrm{C}$ in serum

\begin{tabular}{|c|c|c|c|c|c|c|}
\hline \multirow[t]{3}{*}{ A } & \multirow{2}{*}{\multicolumn{2}{|c|}{$\begin{array}{l}20 \mathrm{mM} \text { Histidine } / 240 \mathrm{mM} \text { sucrose } \\
4{ }^{\circ} \mathrm{C}\end{array}$}} & \multirow{2}{*}{\multicolumn{2}{|c|}{$\begin{array}{l}0.9 \% \mathrm{NaCl} \\
4{ }^{\circ} \mathrm{C}\end{array}$}} & \multirow{2}{*}{\multicolumn{2}{|c|}{$\begin{array}{l}\text { Serum } \\
37^{\circ} \mathrm{C}\end{array}$}} \\
\hline & & & & & & \\
\hline & $\begin{array}{l}\text { Radiochemical } \\
\text { purity }(\%)\end{array}$ & $\begin{array}{c}\text { Immunoreactive } \\
\text { fraction }(\%)\end{array}$ & $\begin{array}{l}\text { Radiochemical } \\
\text { purity }(\%)\end{array}$ & $\begin{array}{c}\text { Immunoreactive } \\
\text { fraction }(\%)\end{array}$ & $\begin{array}{c}\text { Radiochemical } \\
\text { purity }(\%)\end{array}$ & $\begin{array}{c}\text { Immunoreactive } \\
\text { fraction }(\%)\end{array}$ \\
\hline $0 \mathrm{~h}$ & 99.0 & 98 & 98.0 & 97 & 100.0 & 97 \\
\hline $24 \mathrm{~h}$ & 98.4 & 97 & 97.8 & 95 & 100.0 & nd \\
\hline $48 \mathrm{~h}$ & 97.7 & 96 & 95.1 & 93 & 99.2 & nd \\
\hline $72 \mathrm{~h}$ & 97.0 & 94 & 94.5 & 91 & 97.5 & 91 \\
\hline $168 \mathrm{~h}$ & 92.5 & 90 & 89.1 & 82 & 96.3 & 88 \\
\hline \multirow[t]{3}{*}{ B } & \multicolumn{2}{|c|}{$20 \mathrm{mM}$ Histidine $/ 240 \mathrm{mM}$ sucrose } & \multicolumn{2}{|l|}{$0.9 \% \mathrm{NaCl}$} & \multicolumn{2}{|l|}{ Serum } \\
\hline & \multicolumn{2}{|c|}{$4{ }^{\circ} \mathrm{C}$} & \multicolumn{2}{|l|}{$4{ }^{\circ} \mathrm{C}$} & \multicolumn{2}{|l|}{$37^{\circ} \mathrm{C}$} \\
\hline & $\begin{array}{c}\text { Radiochemical } \\
\text { purity }(\%)\end{array}$ & $\begin{array}{c}\text { Immunoreactive } \\
\text { fraction }(\%)\end{array}$ & $\begin{array}{l}\text { Radiochemical } \\
\text { purity }(\%)\end{array}$ & $\begin{array}{c}\text { Immunoreactive } \\
\text { fraction }(\%)\end{array}$ & $\begin{array}{l}\text { Radiochemical } \\
\text { purity }(\%)\end{array}$ & $\begin{array}{c}\text { Immunoreactive } \\
\text { fraction }(\%)\end{array}$ \\
\hline $0 \mathrm{~h}$ & 97.8 & 96 & 98.6 & 97 & 100.0 & 97 \\
\hline $24 \mathrm{~h}$ & 97.2 & 95 & 88.5 & 81 & 88.6 & 85 \\
\hline $48 \mathrm{~h}$ & 96.0 & 93 & 65.8 & nd & 82.3 & 79 \\
\hline $72 \mathrm{~h}$ & 94.9 & 93 & 57.6 & nd & 77.7 & 74 \\
\hline $168 \mathrm{~h}$ & 90.5 & 87 & 50.4 & nd & 72.0 & 64 \\
\hline
\end{tabular}

$n d$ not determined

Radiochemical purity of buffer samples determined by a spin filter

Radiochemical purity of serum samples determined by SEC-HPLC

over ${ }^{89} \mathrm{Zr}$-DFO*-trastuzumab in bone-containing organs increased over time (see Figure S6). At $24 \mathrm{~h}$ p.i., the ratio was 1.3 in sternum and 1.5 in femur; at $72 \mathrm{~h}$ p.i. 1.7 in sternum, 2.1 in femur, and 2.8 in knee; and at 144 h p.i., 3.6 in sternum, 5.0 in femur, and 5.9 in knee (see Figure S6).

PET imaging studies were performed to evaluate ${ }^{89} \mathrm{Zr}$ $\mathrm{DFO}\left({ }^{*}\right)$-trastuzumab uptake also in tissues not evaluated in the ex vivo biodistribution experiment. Movies of PET images that were obtained $72 \mathrm{~h}$ p.i. are provided in the supporting information. While tumor uptake was clearly visible for both ${ }^{89} \mathrm{Zr}$-DFO*-trastuzumab and ${ }^{89} \mathrm{Zr}$-DFO-trastuzumab, ${ }^{89} \mathrm{Zr}$ -

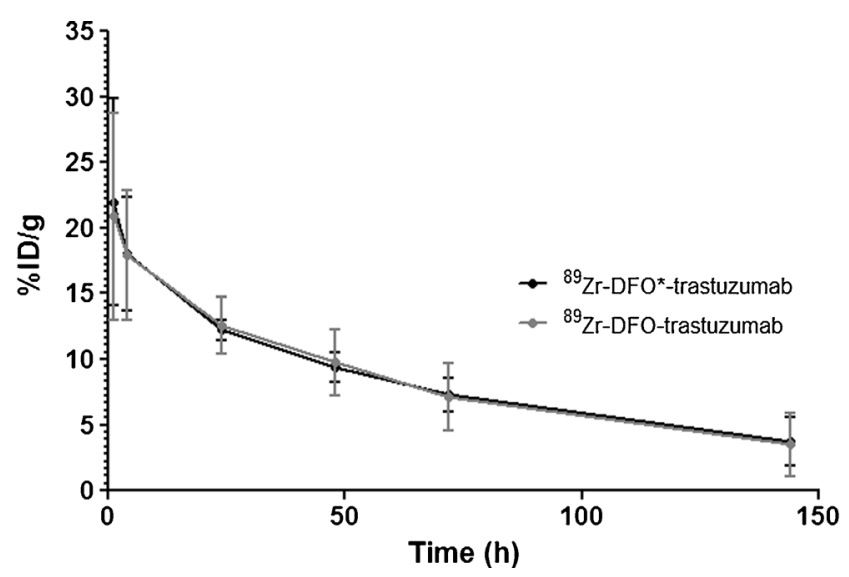

Fig. 2 Blood kinetics of ${ }^{89} \mathrm{Zr}$-DFO*-trastuzumab (black line) and ${ }^{89} \mathrm{Zr}$ DFO-trastuzumab (grey line) in N87 tumor-bearing nude mice up to $144 \mathrm{~h}$ after administration
$\mathrm{DFO}^{*}$-trastuzumab showed less bone uptake than ${ }^{89} \mathrm{Zr}$ DFO-trastuzumab (see Fig. 4).

\section{Discussion}

In the present study, we describe a new bifunctional octadentate chelator for ${ }^{89} \mathrm{Zr}$, which holds great promise to improve clinical ${ }^{89} \mathrm{Zr}$-immuno-PET performance.

Previously, we reported the synthesis of DFO* and the superior in vitro stability of its complex with ${ }^{89} \mathrm{Zr}$ in comparison to ${ }^{89} \mathrm{Zr}$-DFO, also when challenged with an excess of DFO [24]. Here, we describe the synthesis of a bifunctional version of this chelator, $\mathrm{DFO}^{*}-p$ Phe-NCS. This bifunctional chelator is prepared starting from the commercially available DFO, which makes DFO*-based chelating agents attractive candidates for commercialization and wide spread use in clinical nuclear medicine. The GMP compliant synthesis of ${ }^{89} \mathrm{Zr}$ DFO-mAb conjugates has been described before [6] and ${ }^{89} \mathrm{Zr}$ $\mathrm{DFO}^{*}-\mathrm{mAbs}$ are prepared in a similar manner. The only difference is a small adjustment of the conjugation protocol, which resulted in improved integrity for the ${ }^{89} \mathrm{Zr}-\mathrm{DFO}\left({ }^{*}\right)$ $\mathrm{mAb}$ conjugates. The addition of small portions of the chelator in DMSO to mAbs can result in protein aggregation. To prevent this, the addition order was reversed, and the protein added to the chelator instead. In this way protein aggregation could be minimised. The conjugation of DFO*-pPhe-NCS 
Fig. 3 Biodistribution of ${ }^{89} \mathrm{Zr}$ DFO*-trastuzumab (black bars) and ${ }^{89} \mathrm{Zr}$-DFO-trastuzumab (grey bars) in N87 tumor-bearing nude mice at $24 \mathrm{~h} \mathbf{a}, 72 \mathrm{~h} \mathrm{~b}$, and $144 \mathrm{~h} \mathrm{c}$ after administration. Total administered dose $100 \mu \mathrm{g}$. Mean $(\% \mathrm{ID} / \mathrm{g}) \pm \mathrm{SD}$ at each time point after injection $(n=$ six animals per time point per conjugate).

(Significant differences $(P<0.05)$ in biodistribution between both radioimmunoconjugates are marked with an asterisk) a

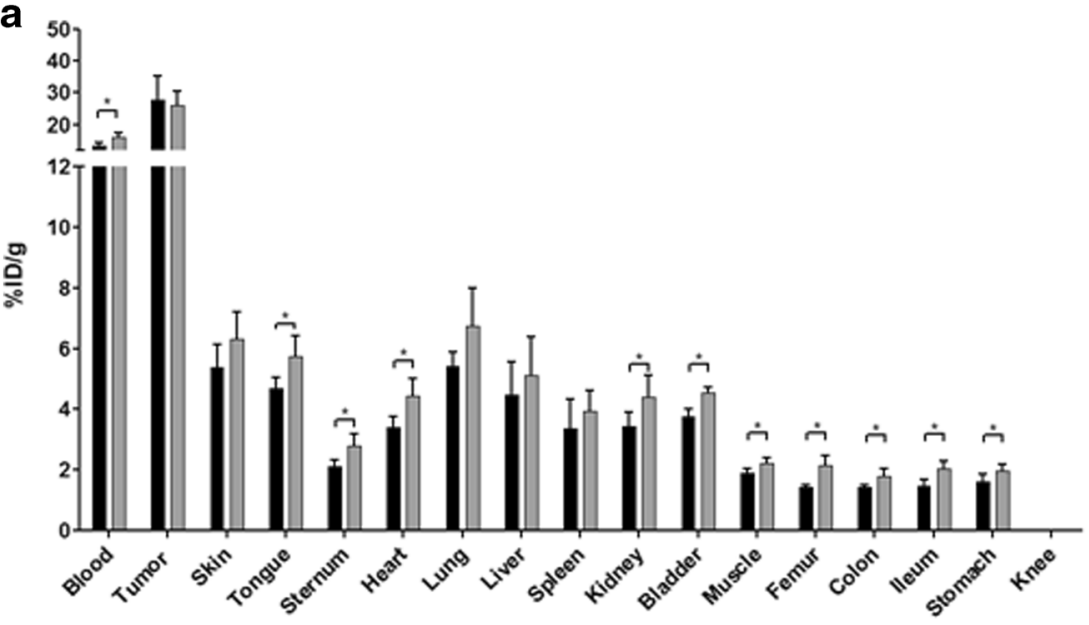

b

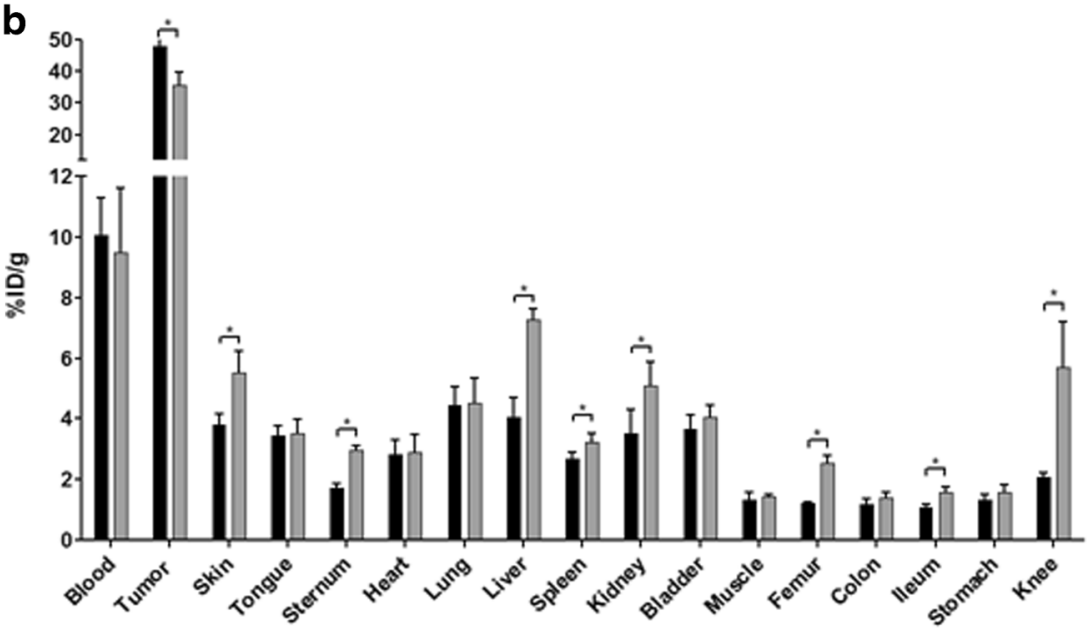

C

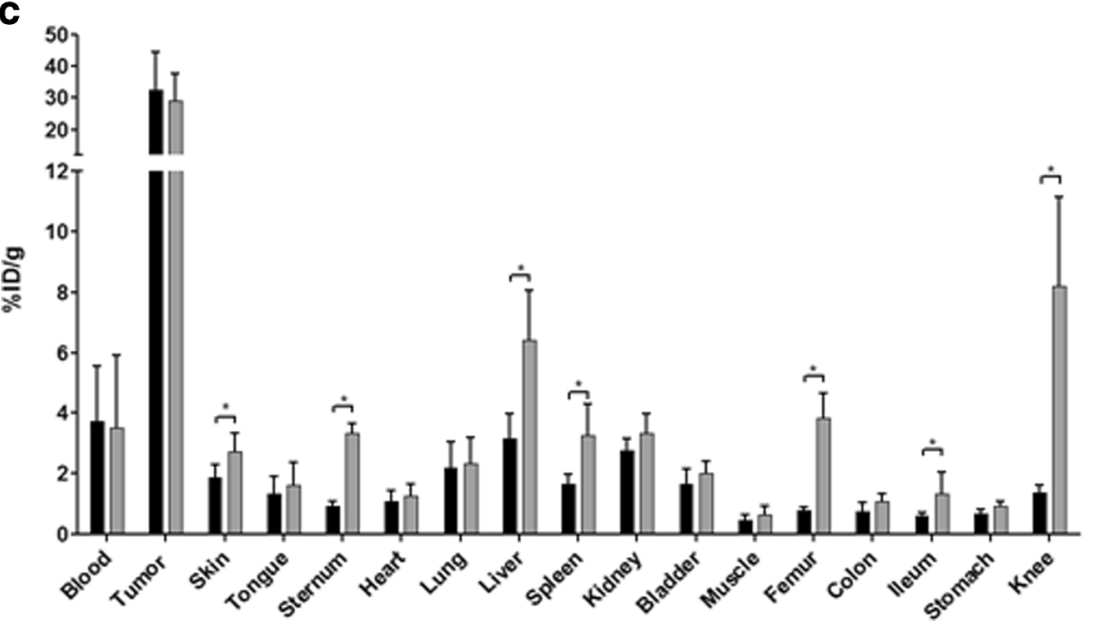

was slightly less effective, but the subsequent radiolabeling efficiency was similar for both chelators. For DFO- $p$ Phe$\mathrm{NCS}$, the same chelator-to-mAb ratios and radiolabeling efficiencies were achieved as reported by Vosjan et al. [6]. Using a prelabeling approach, we found that ${ }^{89} \mathrm{Zr}$-DFO- $p$ Phe-NCS could not be conjugated to mAbs anymore, while ${ }^{89} \mathrm{Zr}$-DFO*$p$ Phe-NCS was still capable of conjugation. This indicates that the isothiocyanate linker may be coordinated to ${ }^{89} \mathrm{Zr}$ in case of DFO and, consequently, is not available anymore for bioconjugation. The same accounts for the $N$-suc-DFO chelator. When $N$-suc-DFO was first radiolabeled with $\mathrm{Zr}-89$, the $\mathrm{COOH}$ group could not be transformed into the TFP-ester anymore [10]. In the case of $\mathrm{DFO}^{*}$; however, ${ }^{89} \mathrm{Zr}$ is coordinatively saturated by the chelator, and; therefore, the 
Fig. 4 Coronal PET images of N87 tumor-bearing nude mice acquired $72 \mathrm{~h}$ after injection of $100 \mu \mathrm{g}, 2 \mathrm{MBq}$ of either ${ }^{89} \mathrm{Zr}$ DFO*-trastuzumab a or ${ }^{89} \mathrm{Zr}$ DFO-trastuzumab b.Tumor are indicated with white arrows, bone uptake is indicated with yellow arrows
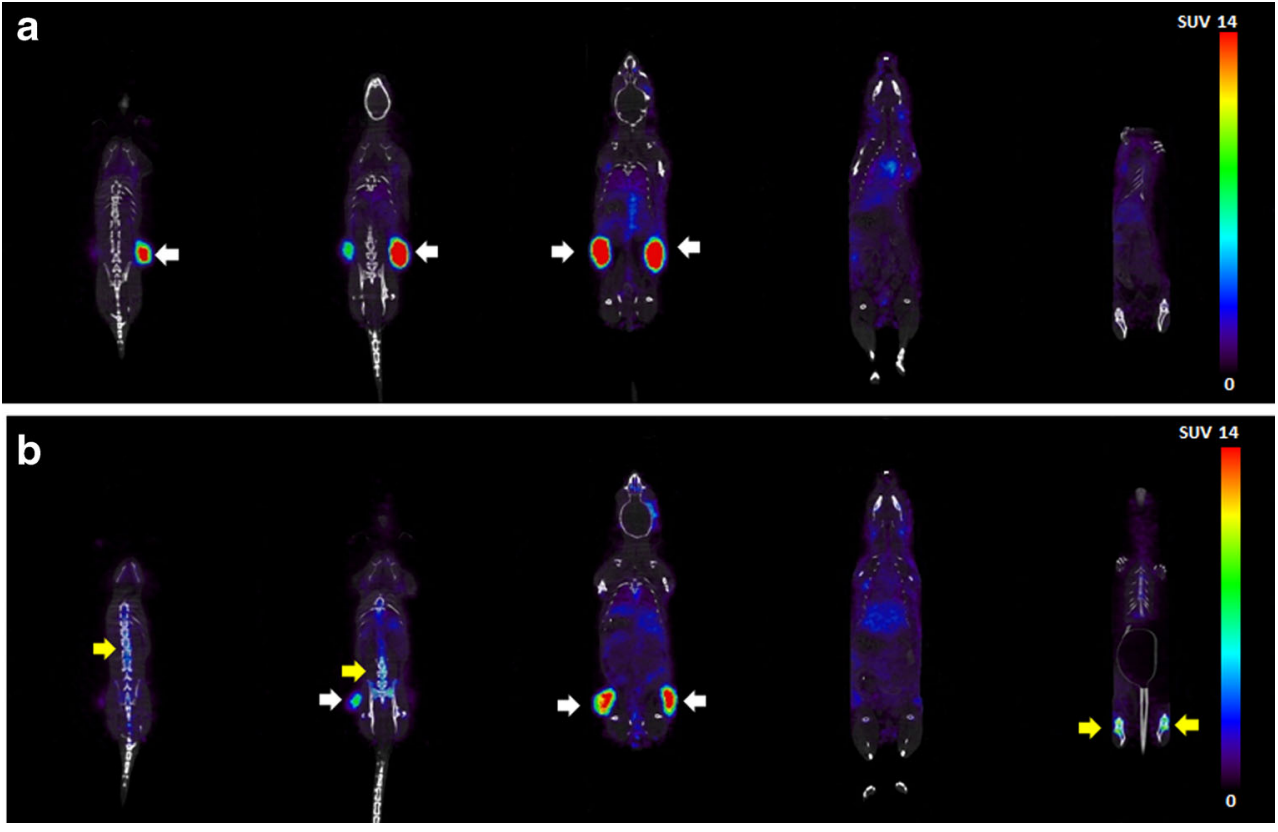

isothiocyanate linker is left available for bioconjugation. This interesting difference now allows prelabeling strategies with ${ }^{89} \mathrm{Zr}$ using $\mathrm{DFO}^{*}$, which was not possible before with DFO derivatives. Prelabeling with ${ }^{89} \mathrm{Zr}$-DFO*-pPhe-NCS could be an advantageous approach in the case of labeling of small amounts of mAb, cells [27], or mAbs with supertoxic payloads, since the number of handlings of the $\mathrm{mAb}$ is reduced from two to one.

The coordinative saturation of ${ }^{89} \mathrm{Zr}$ in $\mathrm{DFO}^{*}$ manifested itself also in vitro and in vivo. While the stability of ${ }^{89} \mathrm{Zr}$ DFO-trastuzumab with thiourea linker is strongly dependent on the storage conditions with respect to buffer composition,

Table 2 Biodistribution of ${ }^{89} \mathrm{Zr}$-DFO*-trastuzumab and ${ }^{89} \mathrm{Zr}$-DFO-trastuzumab in N87 tumor-bearing nude mice at 24, 72 , and $144 \mathrm{~h}$ after administration

\begin{tabular}{|c|c|c|c|c|c|c|c|c|c|c|c|c|c|c|c|c|c|c|}
\hline \multirow{3}{*}{ Blood } & \multicolumn{6}{|l|}{$24 \mathrm{hr}$} & \multicolumn{6}{|l|}{$72 \mathrm{hr}$} & \multicolumn{6}{|l|}{$144 \mathrm{hr}$} \\
\hline & \multicolumn{3}{|l|}{ DFO* } & \multicolumn{3}{|l|}{ DFO } & \multicolumn{3}{|l|}{ DFO* } & \multicolumn{3}{|l|}{ DFO } & \multicolumn{3}{|l|}{ DFO* } & \multicolumn{3}{|l|}{ DFO } \\
\hline & 13.45 & \pm & 1.20 & 16.16 & \pm & 1.47 & 10.06 & \pm & 1.22 & 9.49 & \pm & 2.13 & 3.73 & \pm & 1.84 & 3.50 & \pm & 2.41 \\
\hline Tumor & 27.81 & \pm & 7.44 & 26.23 & \pm & 4.31 & 47.70 & \pm & 5.52 & 35.54 & \pm & 4.08 & 32.59 & \pm & 11.95 & 29.06 & \pm & 8.66 \\
\hline Skin & 5.37 & \pm & 0.75 & 6.31 & \pm & 0.89 & 3.80 & \pm & 0.34 & 5.51 & \pm & 0.73 & 1.88 & \pm & 0.43 & 2.71 & \pm & 0.64 \\
\hline Tongue & 4.69 & \pm & 0.36 & 5.74 & \pm & 0.67 & 3.44 & \pm & 0.33 & 3.52 & \pm & 0.47 & 1.31 & \pm & 0.60 & 1.60 & \pm & 0.76 \\
\hline Sternum & 2.10 & \pm & 0.24 & 2.79 & \pm & 0.39 & 1.72 & \pm & 0.16 & 2.97 & \pm & 0.15 & 0.92 & \pm & 0.16 & 3.33 & \pm & 0.32 \\
\hline Heart & 3.41 & \pm & 0.34 & 4.45 & \pm & 0.58 & 2.82 & \pm & 0.49 & 2.90 & \pm & 0.56 & 1.07 & \pm & 0.35 & 1.25 & \pm & 0.41 \\
\hline Lung & 5.41 & \pm & 0.48 & 6.73 & \pm & 1.28 & 4.43 & \pm & 0.62 & 4.52 & \pm & 0.83 & 2.18 & \pm & 0.88 & 2.32 & \pm & 0.87 \\
\hline Liver & 4.47 & \pm & 1.07 & 5.11 & \pm & 1.26 & 4.05 & \pm & 0.63 & 7.27 & \pm & 0.35 & 3.17 & \pm & 0.82 & 6.43 & \pm & 1.64 \\
\hline Spleen & 3.36 & \pm & 0.99 & 3.95 & \pm & 0.68 & 2.68 & \pm & 0.23 & 3.22 & \pm & 0.30 & 1.65 & \pm & 0.34 & 3.26 & \pm & 1.05 \\
\hline Kidney & 3.43 & \pm & 0.48 & 4.41 & \pm & 0.70 & 3.51 & \pm & 0.78 & 5.08 & \pm & 0.81 & 2.75 & \pm & 0.42 & 3.35 & \pm & 0.62 \\
\hline Bladder & 3.75 & \pm & 0.28 & 4.56 & \pm & 0.19 & 3.65 & \pm & 0.46 & 4.04 & \pm & 0.41 & 1.65 & \pm & 0.50 & 2.01 & \pm & 0.40 \\
\hline Muscle & 1.90 & \pm & 0.13 & 2.23 & \pm & 0.17 & 1.34 & \pm & 0.24 & 1.44 & \pm & 0.05 & 0.46 & \pm & 0.17 & 0.65 & \pm & 0.27 \\
\hline Femur & 1.43 & \pm & 0.08 & 2.15 & \pm & 0.34 & 1.21 & \pm & 0.06 & 2.54 & \pm & 0.25 & 0.78 & \pm & $0, .11$ & 3.85 & \pm & 0.80 \\
\hline Colon & 1.42 & \pm & 0.08 & 1.79 & \pm & 0.25 & 1.18 & \pm & 0.19 & 1.41 & \pm & 0.15 & 0.74 & \pm & 0.29 & 1.06 & \pm & 0.28 \\
\hline Ileum & 1.48 & \pm & 0.21 & 2.03 & \pm & 0.28 & 1.09 & \pm & 0.09 & 1.57 & \pm & 0.20 & 0.60 & \pm & 0.10 & 1.34 & \pm & 0.70 \\
\hline Stomach & 1.61 & \pm & 0.25 & 1.97 & \pm & 0.20 & 1.33 & \pm & 0.18 & 1.57 & \pm & 0.27 & 0.67 & \pm & 0.14 & 0.94 & \pm & 0.12 \\
\hline Knee & n.d. & & & n.d. & & & 2.07 & \pm & 0.15 & 5.70 & \pm & 1.51 & 1.38 & \pm & 0.23 & 8.20 & \pm & 2.94 \\
\hline
\end{tabular}

Total administered dose $100 \mu \mathrm{g}$. Mean $(\% \mathrm{ID} / \mathrm{g}) \pm \mathrm{SD}$ at each time point after injection $(n=$ six animals per time point and conjugate) 
this is less critical for the thiourea-linked ${ }^{89} \mathrm{Zr}$-DFO*trastuzumab. In previous experiments, we found that ${ }^{89} \mathrm{Zr}$ DFO-mAbs having a thiourea linker between DFO and the $\mathrm{mAb}$ should preferably not be stored in sodium chloridecontaining buffers. We postulated that the presence of $\mathrm{Cl}^{-}$ions affected the stability of ${ }^{89} \mathrm{Zr}$-labeled $\mathrm{mAb}$ due to radiationinduced formation of hypochlorite ions reacting with the enolised thiourea unit. Mixing of ${ }^{89} \mathrm{Zr}$-DFO-trastuzumab stored in $0.9 \% \mathrm{NaCl}$ with serum resulted in an increased stability, most probably because sulphur atoms of the serum proteins act as scavenging matter for the hypochlorite. The results in Table 1 show that ${ }^{89} \mathrm{Zr}$-DFO*-mAb with the same thiourea linker is far less sensitive to the presence of $\mathrm{Cl}^{-}$. This indicates that in case of DFO- $p$ Phe-NCS, the enolised sulphur atom of the thiourea unit is coordinated to ${ }^{89} \mathrm{Zr}$ and subsequently oxidised by hypochlorite. These results suggest that the unsaturated coordination of ${ }^{89} \mathrm{Zr}$ is causing the observed impaired stability of the ${ }^{89} \mathrm{Zr}$-DFO complex, which is not seen with the new chelator DFO*.

Although blood kinetics and tumor uptake in mice were similar for ${ }^{89} \mathrm{Zr}$-DFO*-trastuzumab and ${ }^{89} \mathrm{Zr}$-DFOtrastuzumab, ${ }^{89} \mathrm{Zr}$-DFO*-trastuzumab showed a significantly lower uptake in bone containing organs, skin, liver, spleen, and ileum than ${ }^{89} \mathrm{Zr}$-DFO-trastuzumab (Table 2). Actually, over time the bone uptake of ${ }^{89} \mathrm{Zr}$-DFO-trastuzumab increased, while the uptake of ${ }^{89} \mathrm{Zr}$-DFO*-trastuzumab decreased (see Figure S5). Thus, DFO* indeed provides a product that is more stable in vivo, since ${ }^{89} \mathrm{Zr}$ becomes less easily released from the chelator. Recently, much effort has been put in developing improved bifunctional chelators for ${ }^{89} \mathrm{Zr}[16$, $19,20,23]$. Focusing on the bifunctional chelators that coordinate ${ }^{89} \mathrm{Zr}$ efficiently, four molecules have been reported. Derivatised fusarinine C (FSC) [20] a cyclic hexadentate chelator, has been tested in combination with a RGD-peptide. Only short-term in vivo experiments are reported, and the performance with longer circulating biologicals is not yet known. Next, there are two ${ }^{89} \mathrm{Zr}$-HOPO-trastuzumab complexes reported $[16,23]$. Deri et al. reported on ${ }^{89} \mathrm{Zr}$ 3,4,3-(LI-1,2-HOPO)-mAb [16]. Although less bone uptake was observed for ${ }^{89} \mathrm{Zr}-3,4,3$-(LI-1,2-HOPO)-trastuzumab compared to ${ }^{89} \mathrm{Zr}$-DFO-trastuzumab, the tumor uptake also decreased to half of the uptake observed with ${ }^{89} \mathrm{Zr}$-DFOtrastuzumab. Tinianow et al. reported on ${ }^{89} \mathrm{Zr}-2,3-\mathrm{HOPO}-$ trastuzumab [23]. In vitro serum stability, radiochemical purity of the ${ }^{89} \mathrm{Zr}$-labeled mAb complex and in vivo bone uptake were less favorable for ${ }^{89} \mathrm{Zr}-2,3-\mathrm{HOPO}-\mathrm{mAb}$ compared to ${ }^{89} \mathrm{Zr}-\mathrm{DFO}-\mathrm{mAb}$. Finally, Boros et al. reported on a macrocycle-based hydroxamate chelator L5 [19]. Although in vitro stability of their ${ }^{89} \mathrm{Zr}$-chelator was similar to ${ }^{89} \mathrm{Zr}$ DFO, its bifunctional variant coupled to trastuzumab showed higher bone uptake and faster blood clearance than ${ }^{89} \mathrm{Zr}$-DFOtrastuzumab. Though a direct comparison of the described hexadentate/octadentate bifunctional chelators for ${ }^{89} \mathrm{Zr}$ is difficult, indications are that $\mathrm{DFO}^{*}$ is the best qualified with respect to tumor targeting and in vitro and in vivo stability.

\section{Conclusion}

${ }^{89} \mathrm{Zr}$-DFO*-mAbs can be prepared analogously to ${ }^{89} \mathrm{Zr}$-DFO$\mathrm{mAbs}$ resulting in radioimmunoconjugates with high radiochemical purity and optimal immunoreactivity. The in vitro serum stability of ${ }^{89} \mathrm{Zr}$-DFO*-trastuzumab outperformed ${ }^{89} \mathrm{Zr}$ DFO-trastuzumab. In vivo ${ }^{89} \mathrm{Zr}$-DFO*-trastuzumab showed comparable tumor targeting and blood kinetics as ${ }^{89} \mathrm{Zr}$-DFOtrastuzumab, but less uptake in bone-containing organs, skin, liver, spleen, and ileum. This makes DFO* a candidate successor of DFO for clinical ${ }^{89} \mathrm{Zr}$-immuno-PET.

Acknowledgements The authors thank Carla Gotzmann (University of Zurich, Switzerland) for help towards the preparation of starting material.

\section{Compliance of ethical standards}

Funding This work was financially supported by the Swiss National Science Foundation (Professorships $N^{\circ}$ PP00P2_133568 and PP00P2 157545 to G.G and SNSF grant $N^{\circ} 205321-1 \overline{5} 7216$ to G.G. and T.L.M), the University of Zurich (G.G), the Stiftung für Wissenschaftliche Forschung of the University of Zurich (G.G), and the Forschungskredit of the University of Zurich (Grant $N^{\circ}$ K-73532-01-01 to C.M.)

Conflict of interest The authors declare that they have no conflict of interest.

Ethical approval All applicable international, national, and/or institutional guidelines for the care and use of animals were followed.

Open Access This article is distributed under the terms of the Creative Commons Attribution 4.0 International License (http:// creativecommons.org/licenses/by/4.0/), which permits unrestricted use, distribution, and reproduction in any medium, provided you give appropriate credit to the original author(s) and the source, provide a link to the Creative Commons license, and indicate if changes were made.

\section{References}

1. Van Dongen GAMS, Huisman MC, Boellaard R, et al. 89Zrimmuno-PET for imaging of long circulating drugs and disease targets: why, how and when to be applied? Q J Nucl Med Mol Imaging. 2015;59:18-38.

2. Verel I, Visser GWM, Boerman OC, et al. Long-lived positron emitters zirconium-89 and iodine-124 for scouting of therapeutic radioimmunoconjugates with PET. Cancer Biother Biopharm. 2003;18:655-61.

3. Jauw YWS, Menke-van Der Houwen van Oordt CW, Hoekstra OW, et al. Immuno-Positron Emission Tomography with zirconium-89-labeled monoclonal antibodies in oncology: what can we learn from initial clinical trials? Frontiers in Pharmacol. 2016. doi:10.3389/fphar.2016.00131. 
4. Evans JB, Syed BA. From the analyst's couch: next generation antibodies. Nat Rev Drug Discov. 2014;13:413-4.

5. Sliwkowski MX, Mellman I. Antibody therapeutics in cancer. Science. 2013;341:1192-8.

6. Vosjan MJWD, Perk LR, Visser GWM, et al. Conjugation and radiolabeling of monoclonal antibodies with zirconium- 89 for PET imaging using the bifunctional chelate $p$-isothiocyanatobenzyldesferrioxamine. Nat Protoc. 2010;5:739-43.

7. Vugts DJ, Visser GWM, Van Dongen GAMS. ${ }^{89}$ Zr-PET radiochemistry in the development and application of therapeutic monoclonal antibodies and other biologicals. Curr Top Med Chem. 2013;14:446-57.

8. Makris NE, Boellaard R, Visser EP, et al. Multicenter harmonization of ${ }^{89} \mathrm{Zr}$ PET/CT performance. J Nucl Med. 2014;55:264-7.

9. Börjesson PKE, Jauw YWS, Boellaard R, et al. Performance of immuno-positron emission tomography with zirconium-89labeled chimeric monoclonal antibody U36 in the detection of lymph node metastases in head and neck cancer patients. Clin Cancer Res. 2006;12:2133-40.

10. Verel I, Visser GWM, Boellaard R, Stigter-Van Walsum M, Snow GB, Van Dongen GAMS. ${ }^{89} \mathrm{Zr}$ immuno-PET: comprehensive procedures for the production of ${ }^{89} \mathrm{Zr}$-labeled monoclonal antibody. $\mathrm{J}$ Nucl Med. 2003;44:1271-81.

11. Perk LR, Vosjan MJWD, Visser GWM, et al. $p$-Isothiocyanatobenzyldesferrioxamine: a new bifunctional chelate for facile radiolabeling of monoclonal antibodies with zirconium-89 for immuno-PET imaging. Eur J Nucl Med Mol Imaging. 2010;37:250-9.

12. Cohen R, Vugts DJ, Stigter-van Walsum M, Visser GWM, Van Dongen GAMS. Inert coupling of IRDye $800 \mathrm{CW}$ and zirconium89 to monoclonal antibodies for single- or dual-modal fluorescence and PET imaging. Nat Protoc. 2013;8:1010-8.

13. Holland JP, Divilov V, Bander NH, Smith-Jones PM, Larson SM, Lewis JS. ${ }^{89} \mathrm{Zr}$-DFO-J591 for immunoPET of prostate-specific membrane antigen expression in vivo. J Nucl Med. 2010;51:1293-300.

14. Perk LR, Visser GWM, Vosjan MJWD, et al. ${ }^{89} \mathrm{Zr}$ as a PET surrogate radioisotope for scouting biodistribution of the therapeutic radiometals ${ }^{90} \mathrm{Y}$ and ${ }^{177} \mathrm{Lu}$ in tumor-bearing nude mice after coupling to the internalizing antibody cetuximab. J Nucl Med. 2005;46:1898-906.

15. Nayak TK, Garmestani K, Milenic DE, Brechbiel MW. PET and MRI of metastatic peritoneal and pulmonary colorectal cancer in mice with human epidermal growth factor receptor 1 -targeted ${ }^{89} \mathrm{Zr}$ labeled panitumumab. J Nucl Med. 2012;53:113-20.
16. Deri MA, Ponnala S, Kozlowski P, et al. p-SCN-Bn-HOPO: a superior bifunctional chelator for ${ }^{89} \mathrm{Zr}$ immunoPET. Bioconjugate Chem. 2015;26:2579-91.

17. Guérard F, Lee Y-S, Tripier R, Szajek L, Deschamps JR, Brechbiel MW. Investigation of $\mathrm{Zr}(\mathrm{IV})$ and ${ }^{89} \mathrm{Zr}(\mathrm{IV})$ complexation with hydroxamates: progress towards designing a better chelator than desferrioxamine B for immuno-PET imaging. Chem Commun. 2013;49:1002-4.

18. Guérard F, Lee Y-S, Brechbiel MW. Rational design, synthesis, and evaluation of tetrahydroxamic acid chelators for stable complexation of zirconium(IV). Chem Eur J. 2014;20:5584-91.

19. Boros E, Holland JP, Kenton N, Rotile N, Caravan P. Macrocyclebased hydroxamate ligands for complexation and immunoconjugation of ${ }^{89}$ Zirconium for positron emission tomography (PET) imaging. Chem Plus Chem. 2016;81:274-81.

20. Zhai C, Summer D, Rangger C, et al. Novel bifunctional cyclic chelator for ${ }^{89} \mathrm{Zr}$ labeling-radiolabeling and targeting properties of RGD conjugates. Mol. Pharmaceutics 2015;12-2141-50.

21. Price EW, Zeglis BM, Lewis JS, Adam MJ, Orvig C. $\mathrm{H}_{6}$ phospatrastuzumab: bifunctional methylenephosphate-based chelator with ${ }^{89} \mathrm{Zr},{ }^{111}$ In and ${ }^{177} \mathrm{Lu}$. Dalton Trans. 2014;43:119-31.

22. Deri MA, Ponnala S, Zeglis BM, et al. Alternative chelator for ${ }^{89} \mathrm{Zr}$ radiopharmaceuticals: radiolabeling and evaluation of 3,4,3-(LI-1, 2-HOPO). J Med Chem. 2014;57:4849-60.

23. Tinianow JN, Pandya DN, Pailloux SL, et al. Evaluation of a 3hydroxypyridin-2-one (2,3-HOPO) based macrocyclic chelator for ${ }^{89} \mathrm{Zr}^{4+}$ and its use for immunoPET imaging of HER 2 positive model of ovarian carcinoma in mice. Theranostics. 2016;6:511-21.

24. Patra M, Bauman A, Mari C, et al. An octadentate bifunctional chelating agent for the development of stable zirconium- 89 based molecular imaging probes. Chem Commun. 2014;50:11523-5.

25. Lindmo T, Boven E, Cuttitta F, Fedoroko J, Bunn PA Jr. Determination of the immunoreactive fraction of radiolabeled monoclonal antibodies by linear extrapolation to binding at infinite antigen excess.

26. Meares CF, McCall MJ, Reardan DT, Goodwin DA, Diamanti CI, McTique M. Conjugation of antibodies with bifunctional chelating agents: isothiocyanate and bromoacetamide reagents, methods of analysis, and subsequent addition of metal ions. Anal Biochem. 1984;142:68-78.

27. Bansal A, Pandey MK, Demirhan YE, Nesbitt JJ, Crespo-Diaz RJ, Terziv A, et al. Novel $89 \mathrm{Zr}$ cell labeling approach for PET-based cell trafficking studies. Eur J Nucl Med Mol Imaging Research. 2015;5:19. 